\title{
Postoperative management of iatrogenic membranous tracheobronchial injury following bilateral lung transplant
}

\author{
Ann E. Hwalek, DO, MS, ${ }^{\mathrm{a}}$ Bryan A. Whitson, MD, PhD, ${ }^{\mathrm{a}}$ Desmond D'Souza, MD, ${ }^{\mathrm{b}}$ \\ Brian C. Keller, MD, PhD, ${ }^{\mathrm{c}}$ Sujatha P. Bhandary, $\mathrm{MD},{ }^{\mathrm{d}}$ and Asvin M. Ganapathi, $\mathrm{MD},{ }^{\mathrm{a}}$ Columbus, Ohio
}

\footnotetext{
From the Divisions of ${ }^{\mathrm{a}}$ Cardiac Surgery, ${ }^{\mathrm{b}}$ Thoracic Surgery, ${ }^{\mathrm{c}}$ Pulmonary Disease and Critical Care Medicine, and ${ }^{\mathrm{d} A n e s t h e s i o l o g y}$, The Ohio State University Wexner Medical Center, Columbus, Ohio.

Disclosures: B.A.W. is a consultant for Abbott Laboratories and serves on the Clinical Events Committee of TransMedics OCS. All other authors reported no conflicts of interest.

The Journal policy requires editors and reviewers to disclose conflicts of interest and to decline handling or reviewing manuscripts for which they may have a conflict of interest. The editors and reviewers of this article have no conflicts of interest.

Received for publication Nov 4, 2020; accepted for publication Nov 18, 2020; available ahead of print Dec 7, 2020 .

Address for reprints: Asvin M. Ganapathi, MD, Division of Cardiac Surgery, The Ohio State University Wexner Medical Center, N809 Doan Hall, Columbus, OH 43210 (E-mail: asvin.ganapathi@osumc.edu).

JTCVS Techniques 2021;5:103-5

2666-2507

Copyright (C) 2020 The Authors. Published by Elsevier Inc. on behalf of The American Association for Thoracic Surgery. This is an open access article under the CC BY-NC-ND license (http://creativecommons.org/licenses/bync-nd/4.0/).

https://doi.org/10.1016/j.xjtc.2020.11.015
}

Video clip is available online.

Tracheobronchial injury in lung transplant has not been reported in the literature. We present what is believed to be the first reported case of an adult patient with end-stage chronic obstructive pulmonary disease who underwent a bilateral lung transplant (BLT) and subsequently was found to have a near full-thickness tracheal laceration. We elected to use venovenous (VV) extracorporeal membranous oxygenation (ECMO) in the postinjury setting for management of this iatrogenic, membranous tracheobronchial injury in setting of BLT.

\section{CLINICAL SUMMARY}

A 61-year-old female patient with a history of end-stage chronic obstructive pulmonary disease underwent an uneventful BLT through a bilateral thoracosternotomy and central venoarterial ECMO, with an EZ-Blocker (IQ Medical Ventures BV, Rotterdam, Netherlands), due to institutional preferences, for lung isolation. Immediately following transplant, flexible bronchoscopy revealed intact anastomoses bilaterally, no evidence of reperfusion injury, and a near full-thickness 3-cm tracheal laceration was noted laterally near the junction of the membranous and

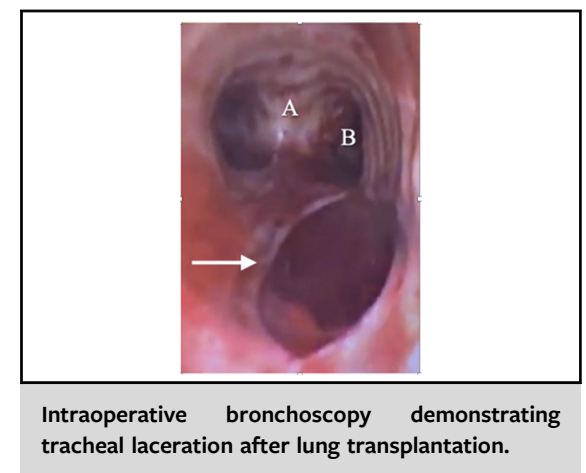

CENTRAL MESSAGE

This case report describes the use of venovenous ECMO in the postinjury setting for management of iatrogenic, membranous tracheobronchial injury following bilateral lung transplantation.

See Commentary on page 106.

cartilaginous trachea from lower thoracic trachea proximal to the right mainstem bronchus (Figure 1, Video 1). The iatrogenic tracheobronchial injury (ITBI) was discovered in the operating room and the decision for nonoperative management was made jointly between cardiothoracic surgery, anesthesia, and transplant pulmonology due to an intact bronchial anastomosis, no air leak on the mediastinal or pleural chest tubes, and no noted tidal volume loss observed on the mechanical ventilation. Subsequent esophagogastroscopy revealed no esophageal injury, and computed tomography of the chest without contrast demonstrated minimal pneumomediastinum adjacent to the lower trachea, which was felt to be consistent with normal postoperative changes.

To minimize deleterious effects of positive pressure ventilation, she was extubated on postoperative day 1 with good allograft function and respiratory effort. Unfortunately, she was reintubated within 2 days for progressive hypoxic and hypercapnic acute respiratory failure. Although stable on mechanical ventilation, there was concern for progression of the ITBI with ongoing positive 


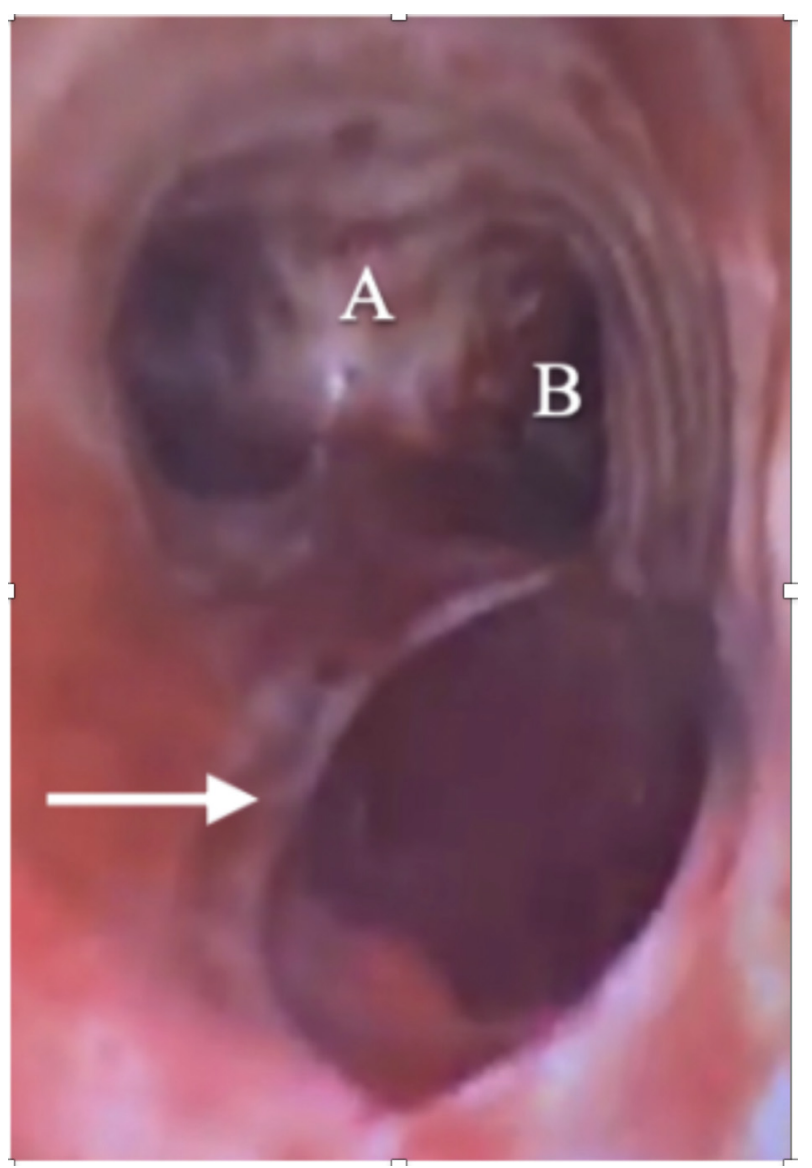

FIGURE 1. Intraoperative bronchoscopy demonstrating tracheal laceration following bilateral lung transplantation. Intraoperative diagnostic bronchoscopy following bilateral lung transplant demonstrating a posterior tracheal laceration (white arrow) proximal to the carina (A) and adjacent to the right mainstem bronchus (B).

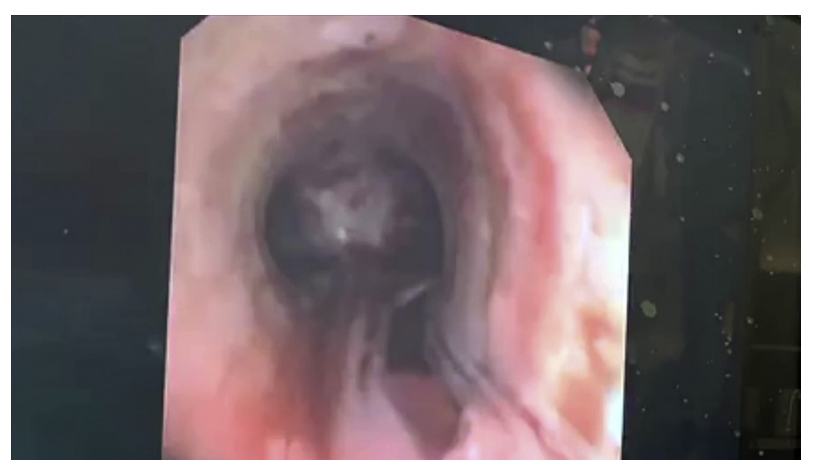

VIDEO 1. Intraoperative bronchoscopy following bilateral lung transplant demonstrating. Live intraoperative diagnostic bronchoscopy near full-thickness $3-\mathrm{cm}$ tracheal laceration was noted laterally near the junction of the membranous and cartilaginous trachea from lower thoracic trachea into the right mainstem bronchus. Respiratory variation can be appreciated with no appreciated change in tidal volume. Video available at: https:// www.jtcvs.org/article/S2666-2507(20)30698-2/fulltext.

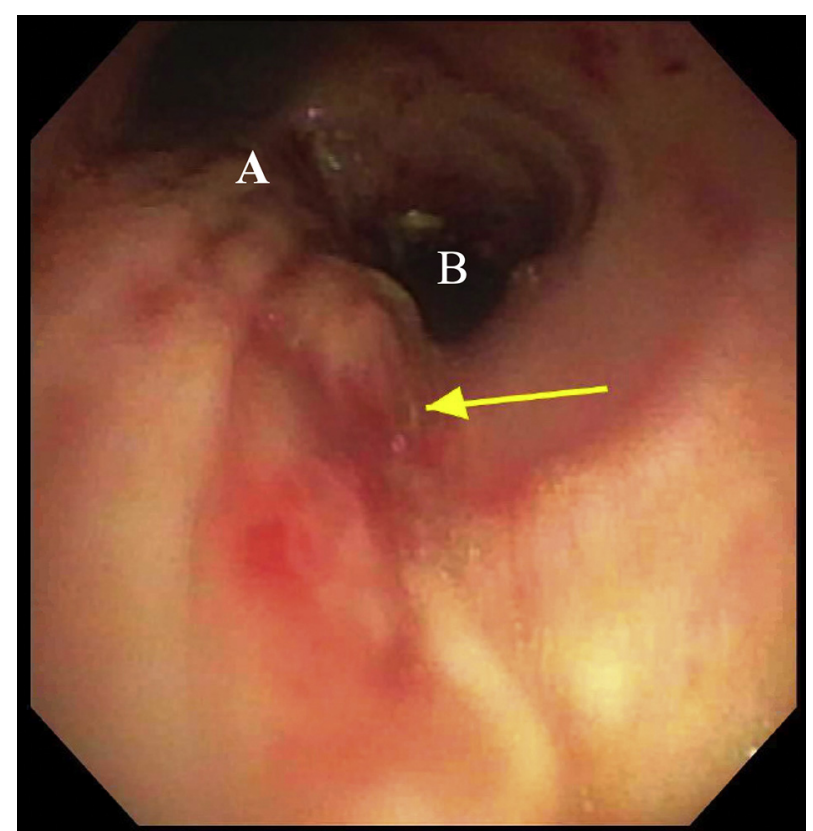

FIGURE 2. Post lung transplant bronchoscopy of healed tracheal laceration. Two-week postoperative diagnostic bronchoscopy without any intervention demonstrating the healing tracheal laceration (yellow arrow) proximal to the carina (A) and adjacent to the right mainstem bronchus (B).

pressure. After a multidisciplinary discussion with lung transplant surgery and pulmonology as well as thoracic surgery, the decision was made to place the patient on VV ECMO with a 31-Fr Avalon Elite Bicaval Dual Lumen catheter (Avalon Laboratories LLC, Rancho Dominguez, Calif) through the right internal jugular vein. The patient was then extubated and slowly weaned from ECMO over a 2-week course. While on ECMO, the patient was mobilized to help aid with her recovery.

A follow-up bronchoscopy showed slow healing of the injury with near resolution by day 13 (Figure 2). Repeat computed tomography scans demonstrated no evidence of pneumomediastinum. The patient was successfully liberated from ECMO 13 days after initiation and ultimately discharged to a rehabilitation facility. Nearly 7 months from the BLT, she continues to do well.

Per the Ohio State University Office of Responsible Research Practices, reviewing 1 or 2 case reports is not considered research involving human subject due to the description of clinical features and/or outcomes of case(s) is not deemed generalizable knowledge.

\section{DISCUSSION}

We report a case the successful management of respiratory failure requiring mechanical ventilatory support of a patient following lung transplantation with supported with VV-ECMO. ITBI has many etiologies, most commonly secondary to mechanical factors such as overinflated cuff, 
sudden or repeated repositioning, and rarely a direct tear from the endotracheal tube. ${ }^{1}$ In our patient, it is not known if the endotracheal tube or the bronchial blocker was the primary etiology or a contributing mechanism to the tracheal injury; however, no identified tracheal abnormality was observed on the preoperative bronchoscopy in the operating room.

Conservative, nonoperative treatment has been well described in stable patient with a short (up to $6 \mathrm{~cm}$ ), membranous wall ITBI. ${ }^{2,3}$ In addition, the use of tracheal stents has been described ${ }^{4}$; however, given the gradual improvement of the bronchial tear coupled with the need for VV ECMO secondary to pulmonary graft dysfunction, a tracheal stent was not considered. Recently, a case report of use of ECMO for the management intraoperative tracheobronchial injury during a transhiatal esophagectomy was published. ${ }^{5}$ In our patient, it was unclear what effect immunosuppression would have on the healing of the tracheal injury; however, given the lack of any subcutaneous emphysema or mediastinitis, the decision was made to treat her nonoperatively and remove positive-pressure ventilation by using VV ECMO. We describe here the safe and effective use of VV ECMO after bilateral lung transplant as management of tracheobronchial injury without associated mediastinitis.

\section{References}

1. Jougon J, Ballester M, Choukroun E, Dubrez J, Reboul G, Velly JF. Conservative treatment for postintubation tracheobronchial rupture. Ann Thorac Surg. 2000;69: 216-20.

2. Gomez-Caro Andres A, Moradiellos Diez FJ, Ausin Herrero P, Diaz-Hellin Gude V, Larru Cabrero E, de Miguel Porch E, et al. Successful conservative management in iatrogenic tracheobronchial injury. Ann Thorac Surg. 2005;79:1872-8.

3. Ross HM, Grant FJ, Wilson RS, Burt ME. Nonoperative management of tracheal laceration during endotracheal intubation. Ann Thorac Surg. 1997;63:240-2.

4. Tazi-Mezalek R, Musani AI, Laroumagne S, Astoul PJ, D'Journo XB, Thomas PA, et al. Airway stenting in the management of iatrogenic tracheal injuries: 10-year experience. Respirology. 2016;21:1452-8.

5. Fermin L, Arnold S, Nunez L, Yakoub D. Extracorporeal membrane oxygenation for repair of tracheal injury during transhiatal esophagectomy. Ann Card Anaesth. 2017;20:S67-9. 